\title{
A Rare Case of Life-Threatening Invasive Mole
}

\author{
Shah R, ${ }^{1}$ Samal AM ${ }^{2}$ \\ Corresponding Author: \\ Dr Rajiv Shah \\ Karnali Academy of health Sciences, Jumla, Nepal \\ Email: rjvshaj512@gmail.com
}

${ }^{1}$ Department of Obstetrics and Gynecology, Karnali Academy of health Sciences, Jumla, Nepal, ${ }^{2}$ Department of General Practice and Emergency Medicine, Karnali Academy of health Sciences, Jumla, Nepal.

\begin{abstract}
:
A 23-year-old female with a known case of partial mole and under hCG follow up presented with acute abdominal pain and signs of hemoperitoneum. Emergency laparotomy revealed a molar pregnancy perforating through the uterine fundus, resulting in massive haemoperitoneum of 4 litres. Total abdominal hysterectomy was done. The serum $\beta$-hCG level regressed following hysterectomy.
\end{abstract}

Keywords: haemoperitoneum; invasive mole; molar pregnancy.

\section{INTRODUCTION}

Invasive mole is also known as Chorioadenoma Destruens. About 15-20\% of complete mole and 3-5\% of partial mole develop into invasive mole. ${ }^{1}$ Molar villi grow into the myometrium or its blood vessels, may extend into the broad ligament and metastasize to the lungs, the vagina or the vulva. All cases of invasive mole are sequelae of hydatidiform moles. The pathologic diagnosis of invasive mole is rarely made because most cases are treated medically, without hysterectomy. ${ }^{7}$

\section{CASE REPORT}

A 23-year female, $\mathrm{G}_{2} \mathrm{P}_{0+1}$ presented for early pregnancy check-up at 8 weeks of gestation. On examination her uterus was abdominally palpable and was about 16 weeks size and bilateral adnexa was free. Her USG scan showed features suggestive of molar pregnancy. So, patient was admitted and suction evacuation was done next day.Her pre-evacuation Serum $\beta$-HCG was 2,07,180mIU/ $\mathrm{ml}$. She was discharged and was under 2 weekly $\beta$-HCG follow-up which was in decreasing trend as shown in fig 4. Her histopathology report showed findings consistent with partial mole.

On $36^{\text {th }}$ day post evacuation patient presented to the Emergency room with complains of pain abdomen for 2 days and 3 episodes of syncopal

attack. On examination patient was pale, her pulse was 132/min and BP 70/30 mmHg. Her abdomen was tense, tender with guarding and rigidity. There was forniceal fullness and tenderness. Resuscitation was started immediately and despite 3 liters of IV fluid blood pressure was 90/60 mm Hg. About 4 pints of blood was also transfused. All the investigations including CBC, coagulation profile, renal function tests and liver function tests were sent USG guided aspiration showed haemoperitoneum. Emergency laparotomy planned after counselling for the possibility of hysterectomy. Intraoperatively findings were hemoperitoneum of about 4 liters, active bleeding from a rent of about $3 \times 3 \mathrm{~cm}$ sizeat fundus anteriorly and fragile uterine tissue. Repair was unsuccessful due to fragility of tissue and so hysterectomy was performed.

She received 14 units blood and 6 units of fresh frozen plasma all together. She was discharged on day 10 and kept on regular serum $\beta$-HCG follow up that regressed following hysterectomy. The histopathology showed invasive mole with transmural infiltration as shown in figure 3. 
Shah et al. A Rare Case of Life-Threatening invasive Mole....

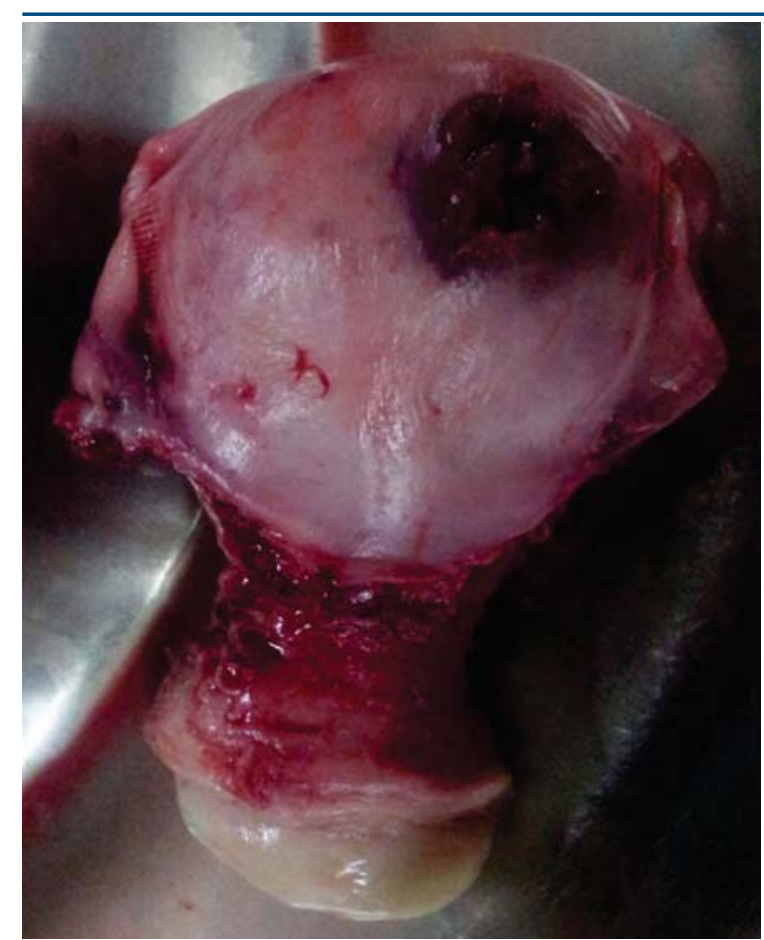

Figure 1. Uterus with perforation

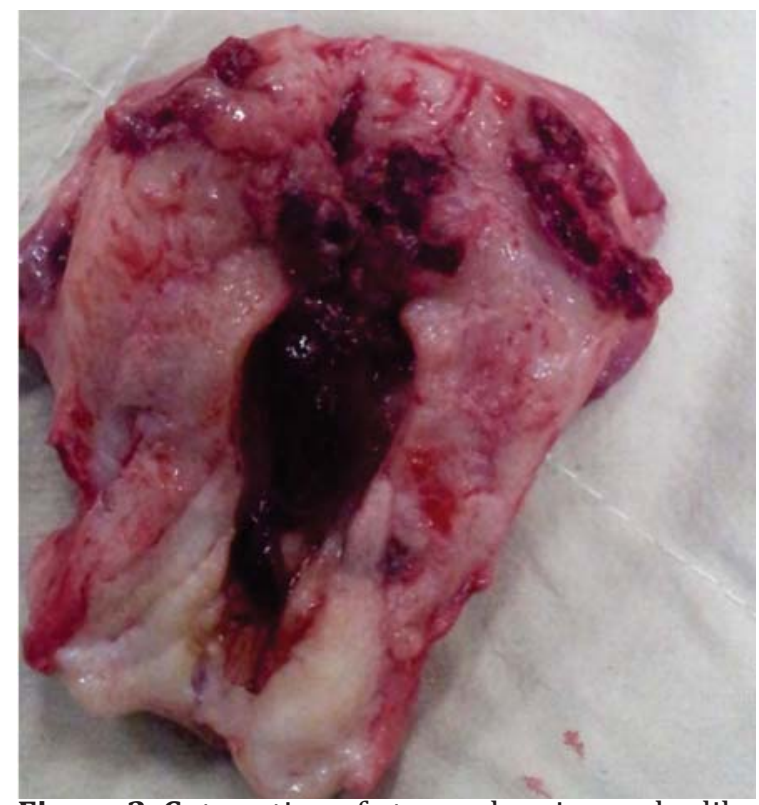

Figure 2. Cut-section of uterus showing molar like tissues invading uterine wall

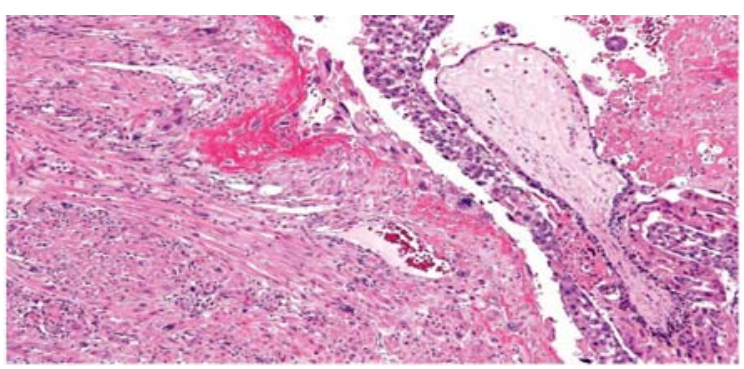

Figure 3. Histological study showing molar tissues penetrating into the myometrium

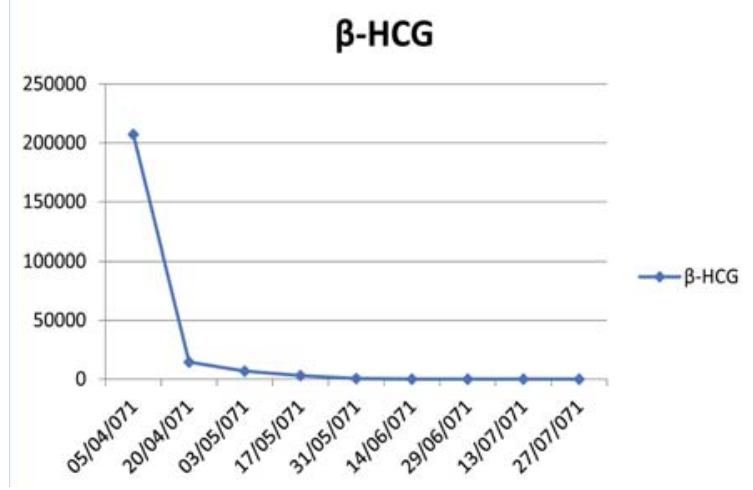

Figure 4. showing decreasing pattern of $\beta$-HCG

\section{DISCUSSION}

An invasive mole causing uterine perforation is a rare occurrence. Invasive mole may perforate through the myometrium resulting in uterine perforation and intraperitoneal bleeding. ${ }^{2}$ Direct vascular invasion and metastasis rarely occurs in invasive moles, the most common site reported is the lung.,4 The diagnosis of invasive mole is made by the demonstration of molar tissues invading the myometrium or the presence of villi in the metastatic lesion. Myometrial invasion is difficult to document onpelvic ultrasound and also in uterine curettage unless thereis a sufficient myometrium to demonstrate the invasion. Intraoperative management options are limited due to the acute presentation.

Mitani et $\mathrm{al}^{5}$ recommended partial resection for young women if invasive moles are complicated by internal hemorrhage. They have reported five women treated this way, four of which subsequently delivered healthy babies by caesarean section. Goldstein et $\mathrm{al}^{6,7}$ used local uterine resection together with bilateral internal iliacartery ligation in an attempt to achieve haemostasis and preserve fertility. In our patient we performed hysterectomy after attempt to repair was failed. Also, partially, due to surgeon being unexperienced with the surgical techniques described above and very critical patient condition. Use of chemotherapy in the management of invasive mole is debatable, with the evidence of spontaneous regression of metastatic mole in the literature. ${ }^{3,4}$ We did not consider chemotherapy in our case as there was no evidence of metastasis and the B-hCG levels was low and thereafter declined and became 
negative. Pronounced degenerative changes in the trophoblast along with hyalinization were found to correlate with low or declining levels of $B$-hCG.

\section{Conflict of Interest: None}

\section{REFERENCES}

1. Soper JT. Gestational trophoblastic disease. ObstetGynecol 2006; 108: 176-187

2. Mackenzie F, Mathers A, Kennedy, J Invasive hydatidiformmole presenting as an acute primary haemoperitoneum.Br J ObstetGynecol1993; 100: 953-54

3. Wilson RB, Hunter IS, Dockerty MB. ChorioadenomaDestruens. Am J Obstet Gynecol. 1961; 81: 546-59

4. Ring AM. The concept of benign metastasizing hydatidiformmoles. Am J Clin Path. 1972; 58:11117

5. Mitani $Y$ et al. Partial resection of the uterus for chorioadenoma destruens. In: Proceedings of the Fifth WorldCongress on Obstetrics and Gynaecology. 1984

6. Gold stein DP \& Berkowitz RS. Gestational Trophoblastic Neoplasia. WB Saunders, Philadelphia 1982; 98-121

7. Kumar S, Vimala N, Mittal S. Invasive Mole Presenting as Acute Haemoperitoneum. JK Scienc 2004;6(3):159. 